\title{
Phase I/II study of first-line irinotecan combined with 5-fluorouracil and folinic acid Mayo Clinic schedule in patients with advanced colorectal cancer
}

\author{
Thomas Kuehr*1, Paul Ruff2, Bernardo L Rapoport ${ }^{3}$, Stephen Falk ${ }^{4}$, \\ Francis Daniel ${ }^{5}$, Conrad Jacobs ${ }^{6}$, Neville Davidson ${ }^{7}$, Josef Thaler ${ }^{1}$, \\ Blandine Boussard $^{8}$ and James Carmichael ${ }^{9}$
}

\begin{abstract}
Address: ${ }^{1}$ Hospital Barmherzige Schwestern vom heiligen Kreuz, Griesskirchner Strasse 42, 4600 Wels, Austria, ${ }^{2}$ Department of Medical Oncology, Johannesburg Hospital, Parktown 2193, South Africa, ${ }^{3}$ The Medical Oncology Centre of Rosebank, Saxonwold, Johannesburg 2196, South Africa, ${ }^{4}$ Bristol Oncology Centre, Bristol BS2 8ED, UK, 5Plymouth Oncology Centre, Derriford Hospital, Plymouth PL6 8DH, UK, ${ }^{6}$ East Cape Oncology Centre, St George's Hospital, Port Elizabeth 6001, South Africa, ${ }^{7}$ Oncology Suite, Broomfield Hospital, Chelmsford CM1 7ET, UK, ${ }^{8}$ Global Medical Affairs Oncology, Aventis, Antony 92165, France and ${ }^{9}$ Cancer Research Campaign Department of Clinical Oncology, City Hospital, Nottingham NG5 1PB, UK

Email: Thomas Kuehr* - thomas.kuehr@khwels.at; Paul Ruff - ruffp@medicine.wits.ac.za; Bernardo L Rapoport - brapoport@icon.co.za; Stephen Falk - stephen.falk@ubht.swest.nhs.uk; Francis Daniel - danielff@phnt.swest.nhs.uk; Conrad Jacobs - conrad.jacobs@cancercare.co.za; Neville Davidson - neville.davidson@meht.nhs.uk; Josef Thaler - josef.thaler@khwels.at; Blandine Boussard - blandine.boussard@aventis.com; James Carmichael - james.carmichael@astrazeneca.com

* Corresponding author
\end{abstract}

Published: 16 July 2004

BMC Cancer 2004, 4:36 doi:10.1 186/147/-2407-4-36

This article is available from: http://www.biomedcentral.com/I47/-2407/4/36

(C) 2004 Kuehr et al; licensee BioMed Central Ltd. This is an Open Access article: verbatim copying and redistribution of this article are permitted in all media for any purpose, provided this notice is preserved along with the article's original URL.

\section{Abstract}

Background: This multicentre phase I/II study was designed to determine the maximum tolerated dose of irinotecan when combined with 5-fluorouracil and folinic acid according to the Mayo Clinic schedule and to evaluate the activity of this combination as first-line therapy in patients with advanced colorectal cancer.

Methods: Sixty-three patients received irinotecan $\left(250\right.$ or $300 \mathrm{mg} / \mathrm{m}^{2}, 30$ - to 90 -minute intravenous infusion on day I), immediately followed by folinic acid $\left(20 \mathrm{mg} / \mathrm{m}^{2} /\right.$ day $)$ and 5 -fluorouracil $\left(425 \mathrm{mg} / \mathrm{m}^{2}\right.$, I5-minute bolus infusion) days I to 5, every four weeks.

Results: Diarrhoea was dose limiting at $300 \mathrm{mg} / \mathrm{m}^{2}$ irinotecan in combination with 5-fluorouracil and folinic acid, and this was determined to be the maximum tolerated dose. Grade 3-4 neutropenia was the most frequently reported toxicity. The recommended dose of irinotecan for the phase II part of the study was $250 \mathrm{mg} / \mathrm{m}^{2}$. The response rate for the evaluable patient population was $36 \%$ (13/36), and $44 \%$ (16 patients) had stable disease (including $19 \%$ of minor response). For the intention-to-treat population, the response rate was $29 \%$ (14/49) and 35\% (I7 patients) stable disease (including 14\% of minor response). The median time to progression was 7.0 months and the median survival was 12.0 months. Grade 3-4 non-haematological drug-related toxicities included delayed diarrhoea, stomatitis, fatigue, and nausea/vomiting. There were three deaths due to septic shock that were possibly or probably treatment-related.

Conclusions: This regimen of irinotecan in combination with the Mayo Clinic schedule of bolus 5-fluorouracil/folinic acid every four weeks showed activity as first-line therapy in patients with advanced colorectal cancer. In keeping with other published results of studies using bolus 5-fluorouracil combined with irinotecan, the use of this regimen is limited by a relatively high rate of grade 3-4 neutropenia, and the combination of irinotecan and infusional 5-fluorouracil / folinic acid should remain the regimen of first choice. 


\section{Background}

Until recently, 5-fluorouracil (5-FU) in combination with folinic acid (FA) has been the mainstay of treatment for advanced colorectal cancer (CRC) $[1,2]$. Of the numerous schedules and doses of 5-FU investigated, the Mayo Clinic bolus schedule, in which both 5-FU and FA are injected daily for five days every four weeks [3-5], emerged as one of the most widely used schedules worldwide for the firstline treatment of advanced CRC.

Irinotecan (CPT-11, Campto ${ }^{\circledast}$ ) is an S-phase specific derivative of camptothecin, which interferes with DNA replication and cell division inhibiting topoisomerase I [6]. Irinotecan demonstrated antitumour activity against metastatic CRC when used alone either as first-line treatment [7-9] or as second-line treatment after the failure of 5-FU [9-12], with overall response rates ranging from $13 \%$ to $32 \%$. In randomised phase III trials, irinotecan administered second-line prolonged survival significantly when compared with either best supportive care [13] or infusional 5-FU/FA [14]. The most frequently reported adverse events associated with irinotecan are neutropenia, delayed diarrhoea, acute cholinergic syndrome, alopecia, fatigue, nausea and vomiting [12].

Early studies in which irinotecan was combined or alternated with 5-FU/FA regimens showed promising first-line efficacy in advanced CRC [15-19]. Two studies had assessed the feasibility of irinotecan (administered every three weeks in the European study or weekly for four weeks followed by two weeks' rest in the US study) alternating with the Mayo Clinic schedule [16,17]. Seventy patients [16] and 33 patients [17] were treated and the overall response rate was around $30 \%$, with a median time to progression of seven months in both studies. The safety profile was satisfactory without overlapping toxicities. These data, coupled with the emerging data from the US and European phase III trials $[20,21]$, suggested that a study of irinotecan in combination with the Mayo Clinic schedule every four weeks was warranted.

The present phase I/II study was designed to determine the maximum tolerated dose (MTD), the recommended dose and the safety profile of irinotecan when combined with the 5-FU/FA Mayo Clinic schedule every four weeks in the treatment of advanced CRC. The antitumour activity of this combination was also evaluated.

\section{Methods \\ Patient eligibility}

Patients with histologically proven, measurable, advanced adenocarcinoma of the colon or rectum, with no potentially resectable metastases, were eligible for inclusion in the study. Other inclusion criteria were: age between 18 and 75 years; a World Health Organization (WHO) per- formance status (PS) 0-2; a life expectancy >3 months; adequate haematological function (haemoglobin $\geq 10 \mathrm{~g} /$ $\mathrm{dL}$, neutrophils $\geq 2 \times 10^{9} / \mathrm{L}$ and platelets $\geq 150 \times 10^{9} / \mathrm{L}$ ); satisfactory renal and hepatic functions (total bilirubin $\leq 1.25 \times$ upper normal limit [UNL], creatinine $\leq 1.25 \times$ UNL, aspartate aminotransferase [ASAT] and alanine aminotransferase [ALAT] $\leq 3 \times \mathrm{UNL}$; or in the case of liver metastases: total bilirubin $\leq 1.5 \times \mathrm{UNL}$, ASAT and ALAT $\leq 5$ $\times$ UNL); no prior chemotherapy or only (neo) adjuvant chemotherapy completed more than six months prior to study entry, and no radiotherapy within the four weeks prior to study entry. Exclusion criteria included: evidence of brain metastases, current infection, unresolved bowel obstruction or sub-acute obstruction, uncontrolled Crohn's disease or ulcerative colitis, and a current history of chronic diarrhoea. This study was approved by the local Ethics Committees of each centre, and conducted in accordance with the Declaration of Helsinski. All patients provided written informed consent. Pretreatment evaluations included a complete medical history and physical examination, complete blood cell count and blood chemistry, electrocardiogram (ECG), complete tumour imaging (X-ray, computed tomography, ultrasound) performed within three weeks before first infusion, and an assessment of tumour markers. The first treatment administration was made within eight days of registration for the study.

\section{Treatment}

Irinotecan (Campto ${ }^{\circledR}$ ) was supplied by Aventis Pharma (Antony, France) as a sterile solution of $20 \mathrm{mg} / \mathrm{ml}$ in $5 \mathrm{ml}$ vials. 5-FU and FA were used in commercially available formulations. Irinotecan (starting at a dose of $250 \mathrm{mg} /$ $\mathrm{m}^{2}$ ) was administered as a 30- to 90-minute intravenous [IV] infusion on day 1, immediately followed by FA 20 $\mathrm{mg} / \mathrm{m}^{2} /$ day IV bolus followed by 5 -FU at a fixed dose of $425 \mathrm{mg} / \mathrm{m}^{2} /$ day IV bolus, on days $1-5$. All patients received a 15-minute bolus infusion of 5-FU/FA. The treatment was administered every four weeks up until disease progression, unacceptable toxicity or withdrawal of patient consent.

Concomitant medication included subcutaneous atropine $0.25 \mathrm{mg}$ as curative treatment for severe cholinergic symptoms, including early diarrhoea. For the treatment of delayed diarrhoea, high-dose loperamide ( $2 \mathrm{mg}$ every two hours for at least 12 hours) was given as soon as the first liquid stool occurred and continued for up to 12 hours after the last liquid stool, without exceeding a total treatment duration of 48 hours. If the diarrhoea persisted for more than 48 hours despite loperamide treatment, or in the case of severe diarrhoea or diarrhoea associated with vomiting, fever or severe neutropenia, patients received a seven-day course of prophylactic broad spectrum oral antibiotics (fluoroquinolone or cotrimoxazole) and were 
hospitalised for rehydration. Patients with febrile neutropenia had to be hospitalised to receive IV antibiotic therapy.

\section{Study design \\ Phase I study}

The starting dose of irinotecan was $250 \mathrm{mg} / \mathrm{m}^{2}$ (dose level I) and the subsequent planned dose levels were $300 \mathrm{mg} /$ $\mathrm{m}^{2}$ (dose level II) and $350 \mathrm{mg} / \mathrm{m}^{2}$ (dose level III). At least three consecutive patients were to be entered at each dose level with a one-week interval between the entry of the first patient and the next two patients. If one out of three patients at one dose level experienced a dose-limiting toxicity (DLT) in the first cycle, at least three more patients were entered at the same dose level. If three out of six patients experienced the same DLT, this dose level was considered to be the MTD of irinotecan in this combination. In the absence of DLT, the next dose level was explored. Once the MTD, as defined above, was reached, the dose immediately below the MTD was explored for determination of the recommended dose. At least six patients were to be included at the MTD and at the recommended dose. Intra-patient dose escalation was not allowed. DLT during the first cycle was defined as the occurrence of any grade 3 or 4 non-haematological toxicity (except alopecia), platelets <25 × 109/L, symptomatic thrombocytopenia (haemorrhage), febrile neutropenia (fever $\geq 38.0^{\circ} \mathrm{C}$ with concomitant grade $3-4$ neutropenia in the absence of documented infection), grade 3-4 infection, grade 4 neutropenia $\geq 7$ days, grade $3-4$ neutropenia associated with severe infection. Second and further cycles of treatment were administered when the neutrophil count was $\geq 1.5 \times 10^{9} / \mathrm{L}$, platelets $\geq 100 \times 10^{9} / \mathrm{L}$ and nonhaematological toxicity (except alopecia) $\leq$ grade 2 , otherwise treatment had to be delayed but not for more than two weeks. If the delay was greater than two weeks, the patient was withdrawn from the study.

\section{Phase II study}

According to the optimal two-stage Simon design [22] used to define the total number of patients required to detect the activity of the treatment, up to 43 evaluable patients had to be included in the study. Dose reductions of $20 \%$ for irinotecan and 5-FU were planned in case of grade 3-4 haematological and/or non-haematological toxicities. There was no dose reduction schedule for FA. As for the phase I part of the study, if the treatment delay was greater than two weeks, the patient was withdrawn from the study.

Relative dose intensities (RDI, the ratio between the actual dose delivered and the planned dose) for the different components of the treatment were regimen were calculated for both the phase I and phase II parts of the study.

\section{Toxicity and response evaluation}

Toxicity, graded according to National Cancer Institute Common Toxicity Criteria (NCI-CTC) version 1, was assessed by clinical examination every cycle, weekly for haematology and every two cycles for biochemistry. Tumour responses were assessed every eight weeks (or two cycles of treatment) using the same method of assessment used at baseline, and according to WHO criteria. Responses were defined as follows: complete response (CR), partial response (PR), minor response (MR), stable disease (SD), and progressive disease (PD). The overall response rate was defined as the percentage of patients with a CR or PR. The duration of response, in responding patients, was calculated from the date of first infusion to the date of documented progression. The time to disease progression (TTP) was calculated from the time of the first infusion to the date of documented progression or death due to malignant disease. Deaths for other reasons than malignant disease were censored.

\section{Statistical analysis}

Analyses were performed using SAS ${ }^{\circledR}$ Software version 8.0 within Windows. The primary end-point of the phase I part of the study was to analyse the DLT observed during the first cycle and to determine the MTD of irinotecan in combination with the 5-FU/FA Mayo Clinic schedule. The secondary objectives were to determine the recommended dose of irinotecan for the phase II part of the study and the safety profile of the combination regimen. In the phase II part of the study, the response rate was reported within 95\% confidence intervals (CI). Efficacy analyses were performed for both the intent-to-treat (ITT) and evaluable (eligible patients with measurable lesion, who had received a minimum of two cycles of treatment, i.e. eight weeks on study) populations.

The Kaplan-Meier method was used to analyse TTP and overall survival. Safety analyses were performed on all patients receiving at least one administration of irinotecan.

\section{Results \\ Patient characteristics}

Between June 19, 1999 and March 26, 2001, 63 patients from three countries (Austria, South Africa, and United Kingdom) were entered: 14 patients in the phase I part of the study and 49 patients in the subsequent phase II part of the study (Table 1). Four patients were not eligible in the phase II part of the study due to the absence of adequate biochemical/haematological function (one of these patients also had no measurable lesion and one had received adjuvant chemotherapy less than six months prior to study entry). Demographic and baseline disease characteristics are listed in Table 1 . Seven men and 7 women with a median age of 59 years entered the phase I 
Table I: Patient characteristics

\begin{tabular}{|c|c|c|}
\hline Characteristics* & Phase I $(n=14)$ & Phase II $(n=49)$ \\
\hline Eligible & 14 (100\%) & 45 (92\%) \\
\hline Evaluable & II (79\%) & $36(73 \%)$ \\
\hline Median age (range) years & $59.0(30.0-69.0)$ & $63.0(37.0-71.0)$ \\
\hline \multicolumn{3}{|l|}{ Sex } \\
\hline Male & $7(50 \%)$ & $33(67 \%)$ \\
\hline Female & $7(50 \%)$ & $16(33 \%)$ \\
\hline \multicolumn{3}{|l|}{ WHO performance status } \\
\hline 0 & $4(29 \%)$ & I4 (29\%) \\
\hline I & $10(71 \%)$ & $31(63 \%)$ \\
\hline 2 & 0 & $4(8 \%)$ \\
\hline \multicolumn{3}{|l|}{ Primary tumour site } \\
\hline Colon & $9(64 \%)$ & 17 (35\%) \\
\hline Rectum & $4(29 \%)$ & $22(45 \%)$ \\
\hline Colon rectosigmoid & I (7\%) & $10(20 \%)$ \\
\hline \multicolumn{3}{|l|}{ Organ involved } \\
\hline Median number & $2(I-4)$ & $2(I-4)$ \\
\hline Liver & $10(71 \%)$ & $42(86 \%)$ \\
\hline Lung & $6(43 \%)$ & 17 (35\%) \\
\hline Lymph node & I (7\%) & $10(20 \%)$ \\
\hline Other soft tissue & 0 & II (22\%) \\
\hline Abdominal cavity & $2(14 \%)$ & $3(6 \%)$ \\
\hline Peritoneum & I (7\%) & 0 \\
\hline Bone & I (7\%) & 0 \\
\hline Skin & 0 & I (2\%) \\
\hline Other & $2(14 \%)$ & $5(10 \%)$ \\
\hline \multicolumn{3}{|l|}{ Prior therapy } \\
\hline Surgery & $12(86 \%)$ & $42(86 \%)$ \\
\hline Radiotherapy & $3(2 \mid \%)$ & $14(29 \%)$ \\
\hline Adjuvant chemotherapy & $4(29 \%)$ & $12(24 \%)$ \\
\hline Surgery + radiotherapy & $3(2 \mid \%)$ & $12(24 \%)$ \\
\hline Surgery + chemotherapy & $4(29 \%)$ & $12(24 \%)$ \\
\hline Radiotherapy + chemotherapy & $2(14 \%)$ & $7(14 \%)$ \\
\hline Surgery + radiotherapy + chemotherapy & $2(14 \%)$ & $7(14 \%)$ \\
\hline
\end{tabular}

*N (\%) unless otherwise stated. WHO = World Health Organization.

part of the study. Thirty-three men and 16 women with a median age of 63 years entered the phase II part of the study. In both parts of the study, the majority of patients had a WHO PS of 1 and two organs involved (median 2, range 1-4), with the liver being the most common site of metastatic disease. Most patients underwent prior surgery ( $86 \%$ in both parts of the study). Prior radiotherapy was given to $21 \%$ of phase I patients and to $29 \%$ of phase II patients. Prior adjuvant chemotherapy had been administered to $29 \%$ and $24 \%$ of phase I and phase II patients, respectively.

\section{Maximum tolerated dose, recommended dose, phase I part of the study}

Six patients received irinotecan at dose level I $(250 \mathrm{mg} /$ $\mathrm{m}^{2}$ ). Eight patients received irinotecan at dose level II $\left(300 \mathrm{mg} / \mathrm{m}^{2}\right)$. DLTs in the first cycle of treatment are shown in Table 2. The MTD was determined to be irinote- can $300 \mathrm{mg} / \mathrm{m}^{2}$ combined with 5 -FU $425 \mathrm{mg} / \mathrm{m}^{2}$ and FA $20 \mathrm{mg} / \mathrm{m}^{2}$. At this dose level, a total of four patients (out of eight) experienced a grade 3 or 4 non-haematological toxicity, comprising diarrhoea (three patients), fatigue or pain (one patient each). The haematological DLT was grade 3-4 neutropenia with severe infection (one patient). The recommended dose level for irinotecan was defined as $250 \mathrm{mg} / \mathrm{m}^{2}$ combined with 5 -FU $425 \mathrm{mg} / \mathrm{m}^{2}$ and FA $20 \mathrm{mg} / \mathrm{m}^{2}$. Of the six patients treated at this dose level, four experienced a non-haematological grade 3-4 toxicity, comprising stomatitis, nausea, fatigue, diarrhoea or pulmonary toxicity. One patient also experienced febrile neutropenia.

\section{Treatment compliance}

\section{Phase I}

In total, 60 cycles of irinotecan combined with 5-FU/FA were administered to 14 patients (median number of 
Table 2: Dose-limiting toxicity during first cycle of irinotecan combined with 5-FU/FA Mayo Clinic schedule according to dose levels in phase I study $(n=14)$

\begin{tabular}{|c|c|c|c|}
\hline Dose level & 1 & II & Overall \\
\hline Irinotecan (mg/m²) & 250 & 300 & $250 / 300$ \\
\hline $5-\mathrm{FU}\left(\mathrm{mg} / \mathrm{m}^{2}\right)$ & 425 & 425 & 425 \\
\hline $\mathrm{FA}\left(\mathrm{mg} / \mathrm{m}^{2}\right)$ & 20 & 20 & 20 \\
\hline \multicolumn{4}{|c|}{ No. of cycles: } \\
\hline Total number & 18 & 42 & 60 \\
\hline Median [range] & $3[1-6]$ & $6[2-8]$ & $4[1--8]$ \\
\hline No. of patients & 6 & 8 & 14 \\
\hline \multicolumn{4}{|c|}{ Dose limiting toxicity (grade)*: } \\
\hline $\begin{array}{l}\text { Any grade 3-4 non-haematological } \\
\text { toxicity: }\end{array}$ & 4 & 4 & 8 \\
\hline Pain (3) & - & 1 & 1 \\
\hline Stomatitis (3) & 1 & - & 1 \\
\hline Nausea (3) & 2 & - & 2 \\
\hline Fatigue (3) & 2 & 1 & 3 \\
\hline Pulmonary (4) & 1 & - & 1 \\
\hline Diarrhoea (3-4) & 2 & 3 & 5 \\
\hline Febrile neutropenia ${ }^{* *}$ & 1 & 0 & 1 \\
\hline Grade 3-4 infection & 0 & 0 & 0 \\
\hline $\begin{array}{l}\text { Grade } 3-4 \text { neutropenia with } \\
\text { severe infection }\end{array}$ & 0 & 1 & 1 \\
\hline No. patients with at least one DLT & $4(67 \%)$ & $4(50 \%)$ & $8(57 \%)$ \\
\hline
\end{tabular}

*Patient may have more than one dose-limiting toxicity (DLT). **Fever $\geq 38.0^{\circ} \mathrm{C}$ with concomitant grade $3-4$ neutropenia in the absence of documented infection.

cycles four, range, $1-8)$. Six cycles $(10 \%)$ were delayed (22\% at dose level I and $5 \%$ at dose level II), and in two cycles (3\%), the dose was reduced due to non-haematological toxicity (one cycle) and prescription error (one cycle).

\section{Phase II}

In total, 218 cycles were administered to 49 patients (median four cycles, range, 1-12). The median RDI was $90 \%$ (range, $52-110 \%$ ) for irinotecan, $88 \%$ (range, $19-$ $108 \%$ ) for 5 -FU and $98 \%$ (range, $20-135 \%$ ) for FA. Atotal of 22 cycles $(10 \%)$ had to be delayed due to haematological (seven cycles) and non-haematological toxicity (six cycles), non-study-related adverse events (two cycles) and other reasons (seven cycles: patient convenience, five cycles; surgery, two cycles). The dose of both irinotecan and 5-FU was reduced in 34 cycles (16\%), due to haematological toxicity ( 15 cycles), non-haematological adverse events (17 cycles), haematological and non-haematological toxicity (one cycle) and weight loss (one cycle).

\section{Haematological toxicity}

\section{Phase I}

Neutropenia was the main adverse event. At dose level I, grade 3-4 neutropenia occurred in $83 \%(5 / 6)$ of patients (Table 3). The median time to neutrophil nadir was 13 days. The median durations of grade 3 and grade 4 neutro- penia were one day and two days, respectively. At dose level II, grade 3-4 neutropenia occurred in $63 \%(5 / 8)$ of patients (Table 3 ). The median time to neutrophil nadir was 20.5 days. At dose level I, grade 3-4 thrombocytopenia occurred in $17 \%(1 / 6)$ of patients. At dose level II, no grade 3-4 thrombocytopenia was observed. Febrile neutropenia was seen in one patient at dose level I, whilst one patient had severe anaemia at dose level II (Table 3).

\section{Phase II}

Neutropenia was also the main adverse event for this phase of the study, with grade 3-4 toxicity reported for $77 \%(38 / 49)$ of patients. Three patients experienced febrile neutropenia. The median time to neutrophil nadir was 15 days. The median duration of grade 3 and grade 4 neutropenia was one day. Grade 3-4 thrombocytopenia and anaemia were infrequent and occurred in one and two patients, respectively.

\section{Non-haematological toxicities \\ Phase I}

The most frequent grade 3-4 non-haematological adverse events possibly or probably related to the treatment were delayed diarrhoea, fatigue, pain, stomatitis, alopecia, nausea, anorexia, vomiting, fever and infection. Grade 3-4 adverse events possibly or probably related to treatment included delayed diarrhoea ( $57 \%$ of patients), fatigue 
Table 3: Haematological toxicity of irinotecan combined with $5-\mathrm{FU} 425 \mathrm{mg} / \mathrm{m}^{2}$ and FA $20 \mathrm{mg} / \mathrm{m}^{2}$ Mayo Clinic schedule (worst grade by patient)

\begin{tabular}{|c|c|c|c|c|c|c|c|c|c|c|c|c|c|c|c|c|}
\hline \multirow[t]{2}{*}{$\begin{array}{l}\text { Dose } \\
\text { level }\end{array}$} & & \multirow[t]{2}{*}{$\begin{array}{c}\text { Irinotecan } \\
\left(\mathrm{mg} / \mathrm{m}^{2}\right)\end{array}$} & \multirow{2}{*}{$\begin{array}{c}\text { No. } \\
\text { of } \\
\text { patients }\end{array}$} & \multicolumn{4}{|c|}{ Neutropenia grade } & \multicolumn{4}{|c|}{$\begin{array}{c}\text { Thrombocytopenia } \\
\text { grade }\end{array}$} & \multicolumn{4}{|c|}{ Anaemia grade } & \multirow[t]{2}{*}{$\begin{array}{c}\text { Febrile } \\
\text { neutropenia }\end{array}$} \\
\hline & & & & I & 2 & 3 & 4 & $\mathbf{I}$ & 2 & 3 & 4 & $\mathbf{I}$ & 2 & 3 & 4 & \\
\hline \multirow[t]{3}{*}{ Phase I } & I & 250 & 6 & 0 & I & I & 4 & 2 & 0 & 1 & 0 & 2 & 3 & 0 & 0 & I \\
\hline & ॥ & 300 & 8 & 1 & 0 & 3 & 2 & I & 0 & 0 & 0 & 0 & 2 & 0 & 1 & 0 \\
\hline & & Overall & 14 & $\begin{array}{c}1 \\
(7 \%)\end{array}$ & $\begin{array}{c}1 \\
(7 \%)\end{array}$ & $\begin{array}{c}4 \\
(29 \%)\end{array}$ & $\begin{array}{c}6 \\
(43 \%)\end{array}$ & $\begin{array}{c}3 \\
(21 \%)\end{array}$ & 0 & $\begin{array}{c}1 \\
(7 \%)\end{array}$ & 0 & $\begin{array}{c}2 \\
(14 \%)\end{array}$ & $\begin{array}{c}5 \\
(36 \%)\end{array}$ & 0 & $\begin{array}{c}1 \\
(7 \%)\end{array}$ & I (7\%) \\
\hline Phase II & & 250 & 49 & $\begin{array}{c}3 \\
(6 \%)\end{array}$ & $\begin{array}{c}6 \\
(12 \%)\end{array}$ & $\begin{array}{c}7 \\
(14 \%)\end{array}$ & $\begin{array}{c}31 \\
(63 \%)\end{array}$ & $\begin{array}{c}8 \\
(16 \%)\end{array}$ & $\begin{array}{c}1 \\
(2 \%)\end{array}$ & 0 & $\begin{array}{c}1 \\
(2 \%)\end{array}$ & $\begin{array}{c}11 \\
(22 \%)\end{array}$ & $\begin{array}{c}9 \\
(18 \%)\end{array}$ & $\begin{array}{c}2 \\
(4 \%)\end{array}$ & 0 & $3(6 \%)$ \\
\hline
\end{tabular}

Table 4: Most common grade 3-4 non-haematological toxicity possibly or probably related to irinotecan combined with 5-FU/FA Mayo Clinic schedule according to dose levels (worst grade by patient)

\begin{tabular}{|c|c|c|c|c|}
\hline \multirow[t]{2}{*}{ Dose level } & \multicolumn{3}{|c|}{ Phase I } & \multirow[t]{2}{*}{ Phase II } \\
\hline & $\mathbf{I}$ & II & Overall & \\
\hline Irinotecan (mg/m²) & 250 & 300 & $250 / 300$ & 250 \\
\hline $5-\mathrm{FU}\left(\mathrm{mg} / \mathrm{m}^{2}\right)$ & 425 & 425 & 425 & 425 \\
\hline $\mathrm{FA}\left(\mathrm{mg} / \mathrm{m}^{2}\right)$ & 20 & 20 & 20 & 20 \\
\hline Number of patients & 6 & 8 & 14 & 49 \\
\hline Delayed diarrhoea & 4 & 4 & $8(57 \%)$ & $16(33 \%)$ \\
\hline Fatigue & 2 & 3 & $5(36 \%)$ & II (22\%) \\
\hline Pain & 3 & 1 & $4(29 \%)$ & $9(18 \%)$ \\
\hline Stomatitis & 4 & I & $5(36 \%)$ & $13(26 \%)$ \\
\hline Alopecia & I & 0 & I (7\%) & $2(4 \%)$ \\
\hline Nausea & 2 & 0 & $2(14 \%)$ & $8(16 \%)$ \\
\hline Anorexia & 1 & 1 & $2(14 \%)$ & 0 \\
\hline Vomiting & I & 0 & I (7\%) & 7 (I4\%) \\
\hline Fever & 0 & I & I (7\%) & 0 \\
\hline Infection & 0 & 0 & 0 & $8(16 \%)$ \\
\hline
\end{tabular}

(36\% of patients), stomatitis (36\% of patients), and pain (29\% of patients) (Table 4 ). Hepatic tolerance was very good (no grade 3/4 increase for transaminases).

\section{Phase II}

The safety profile of the recommended dose combination was close to that observed for the phase I patients. Grade 3-4 adverse events related to study drugs included diarrhoea in $33 \%$ of patients, stomatitis in $26 \%$ of patients, fatigue in $22 \%$ of patients, infection in $16 \%$ of patients, nausea in $16 \%$ of patients, vomiting in $14 \%$ of patients, and pain in $18 \%$ of patients (Table 4 ). Hepatic tolerance was good: one patient had a grade 3 increase in alkaline phosphatase and one had a grade 3 increase in bilirubin. However, three (out of 49) patients died of neutropenic septic shock during the first cycle due to probable or possible treatment-related toxicity (these deaths occurred within the first fifteen days of treatment). One of these patients had a WHO PS of 1 and two had a WHO PS of 2.

\section{Efficacy results}

Phase I

In the phase I part of the study, three eligible patients were not evaluable for efficacy because two full cycles of treatment were not completed $(n=1)$ and/or the method of tumour assessment following treatment differed from that used at baseline $(n=3)$. PRs were seen in $18 \%(2 / 11)$ of evaluable patients $(0 / 4$ at dose level $I$ and $2 / 7$ at dose level II). In addition, $45 \%$ of evaluable patients had at least stabilisation of their disease (four MR and one SD).

Phase II

In the phase II part of the study, nine of the eligible patients were not evaluable for efficacy because two full 
Table 5: Efficacy of irinotecan $250 \mathrm{mg} / \mathrm{m}^{2}$ combined with 5-FU $425 \mathrm{mg} / \mathrm{m}^{2}$ and FA $20 \mathrm{mg} / \mathrm{m}^{2}$ Mayo Clinic schedule in patients in phase II study

\begin{tabular}{|c|c|c|c|c|}
\hline & \multicolumn{2}{|c|}{ Evaluable population $(n=36)$} & \multicolumn{2}{|c|}{ ITT population $(n=49)$} \\
\hline & No. & $\%$ & No. & $\%$ \\
\hline Complete response & 3 & 8 & 3 & 6 \\
\hline Partial response & 10 & 28 & 11 & 22 \\
\hline Minor response & 7 & 19 & 7 & 14 \\
\hline Stable disease & 9 & 25 & 10 & 20 \\
\hline Progressive disease & 7 & 19 & 8 & 16 \\
\hline Not evaluable* & - & - & 10 & 20 \\
\hline Overall response rate $(95 \% \mathrm{Cl}), \%$ & \multicolumn{2}{|c|}{$36(2 I-54)$} & \multicolumn{2}{|c|}{$29(16-42)$} \\
\hline Median duration of response $(95 \% \mathrm{Cl})$, months & \multicolumn{2}{|c|}{$10.4(5.9-11.1)$} & \multicolumn{2}{|c|}{$10.4(4.5-11.1)$} \\
\hline Median duration of stabilisation $(95 \% \mathrm{Cl})$, months & \multicolumn{2}{|c|}{$5.8(4.0-8.3)$} & \multicolumn{2}{|c|}{$6.4(4.0-8.3)$} \\
\hline Median time to progression $(95 \% \mathrm{Cl})$, months & \multicolumn{2}{|c|}{$7.0(4.5-10.1)$} & \multicolumn{2}{|c|}{$5.9(4.0-8.1)$} \\
\hline Median time of survival (range), months & \multicolumn{2}{|c|}{-} & \multicolumn{2}{|c|}{$12.0(8.0-15.2)$} \\
\hline
\end{tabular}

*Nine patients did not receive two full cycles and had method of measurement different from baseline and one patient had method of measurement different from baseline.

cycles of treatment were not completed $(n=8)$ and/or the method of tumour assessment following treatment differed from that used at baseline $(\mathrm{n}=9)$. Among evaluable patients there were three CR and $10 \mathrm{PR}$, giving an overall response rate of $36 \%(13 / 36)(29 \%$ in the ITT population) (Table 5). Seven patients had a MR and nine patients had SD, leading to $44 \%$ SD. The median duration of stabilisation was 5.8 months (95\% CI, 4.0-8.3 months). The median duration of response was 10.4 months $(95 \% \mathrm{CI}$, 5.9-11.1 months). The median TTP was 7.0 months (95\% CI, 4.5-10.1 months) in the evaluable population and 5.9 months (95\% CI, 4.0-8.1 months) in the ITT population (Figure 1). The median survival time was 12.0 months (95\% CI, 8.0-15.2 months) (Figure 2).

\section{Discussion}

The main objective of this multicentre, open phase I/II study was to evaluate the efficacy of the combination of irinotecan administered as a 30- to 90-minute IV infusion combined with the commonly used 5-FU/FA Mayo Clinic schedule (bolus infusion daily for five days, every four weeks) in patients with advanced CRC after determination of the recommended dose in the phase I part of study. Delayed diarrhoea was dose limiting at an irinotecan dose level of $300 \mathrm{mg} / \mathrm{m}^{2}$ (dose level II) combined with 5-FU $425 \mathrm{mg} / \mathrm{m}^{2}$ and FA $20 \mathrm{mg} / \mathrm{m}^{2}$. The recommended dose for the phase II part of the study was, therefore, irinotecan $250 \mathrm{mg} / \mathrm{m}^{2}$ combined with 5 -FU $425 \mathrm{mg} / \mathrm{m}^{2}$ (as a $15-$ minute IV bolus) and FA $20 \mathrm{mg} / \mathrm{m}^{2}$. At this dose level, 18 cycles of irinotecan were administered to six patients in the phase I part of the study and 218 cycles to 49 patients in the phase II part of the study. In the phase II study, the median RDI was superior or equal to $87 \%$ for each drug.
The combination of irinotecan and 5-FU/FA demonstrated clinical activity, as evidenced by an overall response rate of $29 \%$ among the ITT population and of $36 \%$ among the evaluable population. This is similar to the response rate reported recently in a phase II study of an alternating regimen of irinotecan and the Mayo Clinic schedule (30\%) [23]. However, the response rate is lower than that reported among the ITT populations of a phase II study investigating the Nordic bi-weekly schedule of irinotecan/bolus FU/FA (39\%) [24]. While our study was being conducted, results were published from the two pivotal phase III randomised trials confirming the benefits of irinotecan combined with either the bi-weekly de Gramont or the weekly German A.I.O. (Arbeitsgemeinschaft Internische Onkologie) infusional regimens (European trial) [21] or the weekly bolus Saltz regimen (North American trial) [20] compared with 5-FU/FA alone. The response rates in the ITT populations of the irinotecancontaining arms of both trials (35\% and 50\%) were higher than that seen in our current study. The median TTP was similar in our study, the phase II study using the alternating irinotecan/Mayo Clinic schedule and the phase III trials (approximately 7.0 months). However, the median survival time in the ITT populations were higher in both the phase II alternating irinotecan/Mayo Clinic study (17 months) [23] and the phase III trials (14.8 and 17.4 months) $[20,21]$ than in our study (12.0 months). One possible explanation for the shorter median survival time observed in our study could be the relatively lower dose of irinotecan used $\left(250 \mathrm{mg} / \mathrm{m}^{2}\right.$ every four weeks), compared with the doses used in the European trial $(80$ $\mathrm{mg} / \mathrm{m}^{2} /$ week or $180 \mathrm{mg} / \mathrm{m}^{2} / 2$ weeks) [21] and the American trial $\left(125 \mathrm{mg} / \mathrm{m}^{2} /\right.$ week $)$ [20]. However, the recently reported trial of alternating irinotecan/Mayo Clinic sched- 


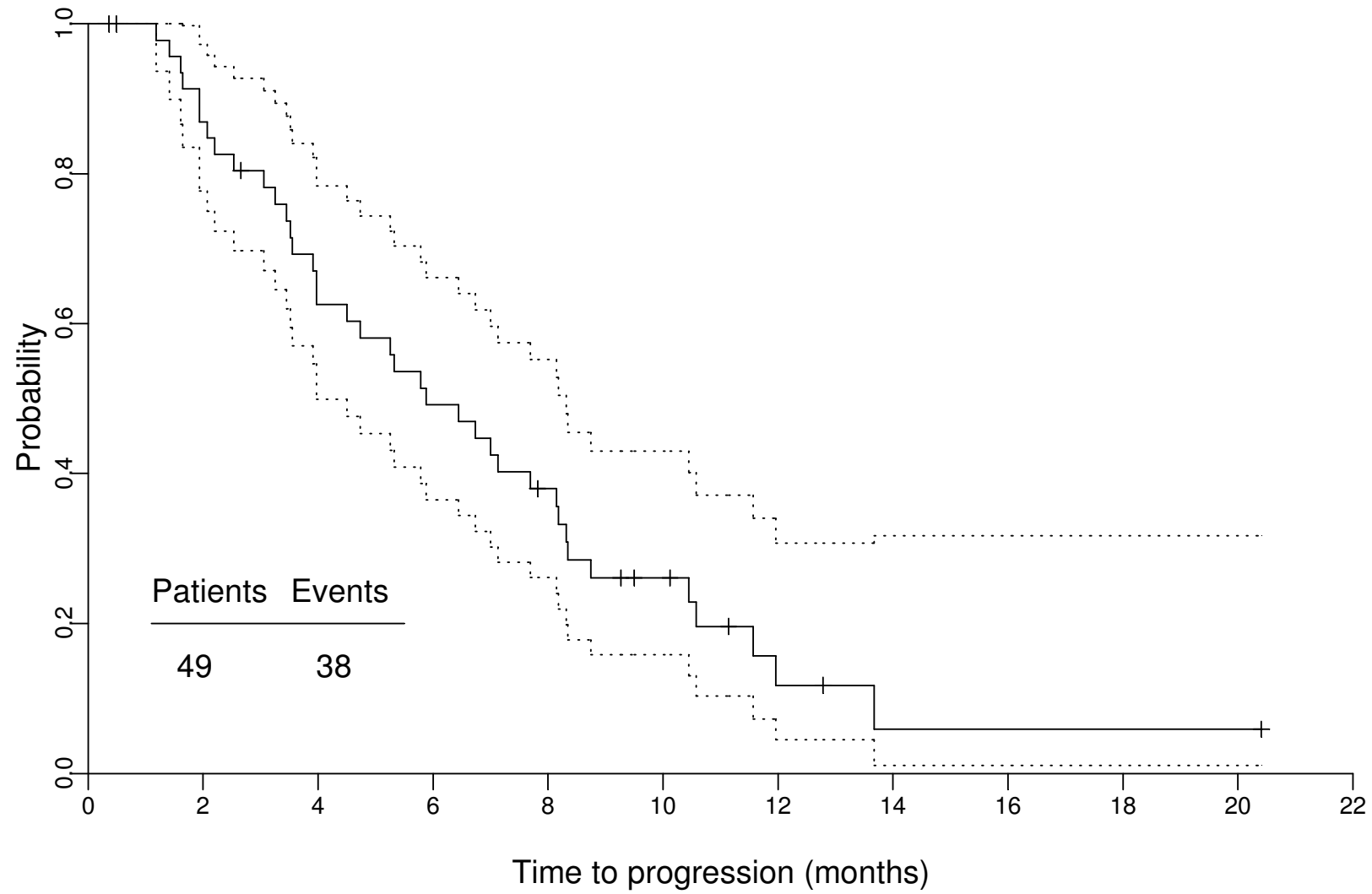

Figure I

Kaplan-Meier plot of time to progression in ITT population Three patients were censored (I at 0.4 months, 2 at 0.5 months) due to deaths from neutropenic sepsis related to study treatment. The patient censored at 2.7 months died of bowel obstruction not related to study treatment.

ule used an irinotecan dose of $350 \mathrm{mg} / \mathrm{m}^{2}$ every six weeks [23]. It is possible therefore that the schedule of administration may be an influencing factor in outcome.

In the present study, neutropenia was the main toxicity. The incidence of grade 3-4 neutropenia in the phase II part of the study (77\% of patients) was comparable to that reported by Buroker et al. with the 5-FU/FA Mayo Clinic schedule alone [4]. However, it was higher than that reported with an alternating schedule of irinotecan/Mayo Clinic schedule [23] and that reported by Saltz et al. in their phase III study comparing irinotecan/bolus 5-FU/FA (54\%) with 5-FU/FA Mayo Clinic schedule alone (66\%) [20]. Although the incidence of grade 3-4 delayed diarrhoea in the present study (33\% of patients in the phase II study) was comparable to that obtained with irinotecan as a single agent $[20,25,26]$, it was higher than that reported with the alternating irinotecan/Mayo Clinic schedule
(22\%) [23] and the Saltz irinotecan/bolus 5-FU/FA (23\%) regimen [20]. The incidences of grade 3-4 infection (16\% of patients) and grade $3-4$ stomatitis (26\% of patients) were also significant in the phase II part of our study.

Three treatment-related deaths occurred within the 60 days after the first infusion and were due to complications following haematological toxicity. Since the initiation of this trial, data have been published regarding the association between some regimens of bolus 5-FU/FA, in combination with irinotecan or oxaliplatin, and early deaths of patients [27-29]. Recommendations of an independent panel for the use of irinotecan plus bolus 5-FU/FA include the weekly assessment of patients, particularly up until week 3 or 4 of treatment, and the prompt management of diarrhoea and/or neutropenia and/or fever [28]. 


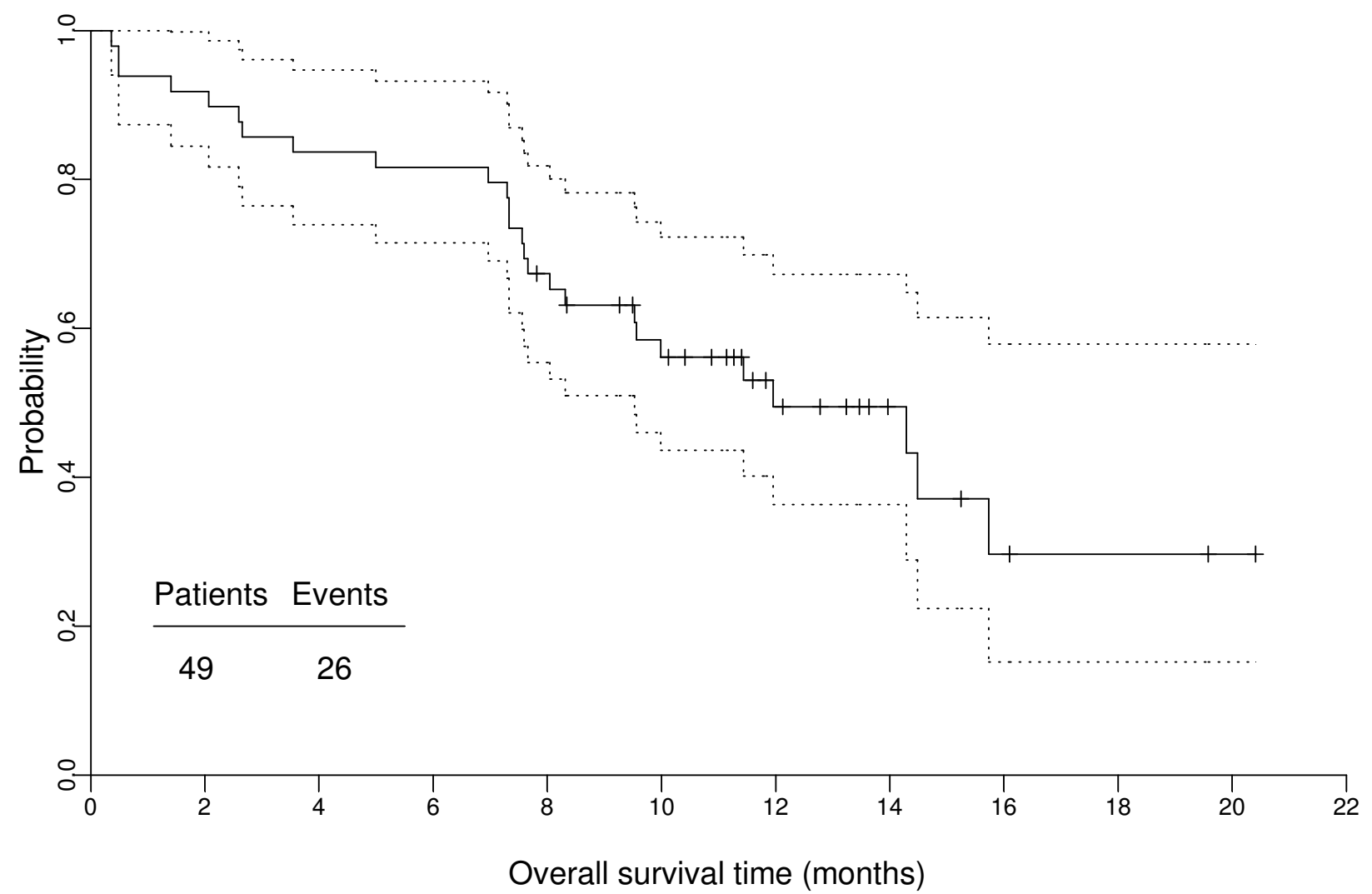

Figure 2

Kaplan-Meier plot of overall survival in ITT population

\section{Conclusions}

Although infusional regimens of 5-FU/FA in combination with irinotecan seem to have better safety profiles than the use of bolus 5-FU/FA, they are not always a practical therapeutic option, and bolus-based regimens still have a role to play in the treatment of metastatic CRC. The results of the present phase I/II study show that the combination of irinotecan $\left(250 \mathrm{mg} / \mathrm{m}^{2}\right)$ and the Mayo Clinic schedule of bolus 5-FU/FA administered once every four weeks demonstrated activity in the first-line treatment of metastatic CRC. However, this regimen was associated with a relatively high level of neutropenia. Three treatment-related deaths amongst 49 patients were reported. Therefore, this regimen requires a close follow-up of the patients. Infusional 5-FU/FA in combination with irinotecan should be the regimen of choice instead of bolus 5-FU/FA.

\section{Competing interests}

None declared.

\section{Authors' contributions}

TK was the chairman of the study. He had the initial idea for the study and participated in the writing of the protocol and review of the draft manuscript.

TK, PR, BR, SF, FD, CJ, ND, JT and JC were investigators on the study and participated in the review and commentary of documents relative to the study.

Final editing of the manuscript was performed by TK, PR, $\mathrm{BR}$ and $\mathrm{BB}$.

All authors read and approved the final manuscript.

\section{References}

I. The Advanced Colorectal Cancer Meta-Analysis Project: Modulation of fluorouracil by leucovorin in patients with advanced colorectal cancer: evidence in terms of response rate. J Clin Oncol 1992, 10:896-903.

2. The Advanced Colorectal Cancer Meta-Analysis Project: Meta-analysis of randomized trials testing the biochemical modulation 
of fluorouracil by methotrexate in metastatic colorectal cancer. J Clin Oncol 1994, 1 2:960-969.

3. Poon MA, O'Connell MJ, Moertel CG, Wieand HS, Cullinan SA, Everson LK, Krook JE, Mailliard JA, Laurie JA, Tschetter LK: Biochemical modulation of fluorouracil: evidence of significant improvement of survival and quality of life in patients with advanced colorectal carcinoma. / Clin Oncol 1989, 7:| 407-|4|8.

4. Buroker TR, O'Connell MJ, Wieand HS, Krook JE, Gerstner JB, Mailliard JA, Schaefer PL, Levitt R, Kardinal CG, Gesme DH Jr: Randomized comparison of two schedules of fluorouracil and leucovorin in the treatment of advanced colorectal cancer.J Clin Oncol 1994, I 2:|4-20.

5. Leichman CG, Fleming TR, Muggia FM, Tangen CM, Ardalan B, Doroshow JH, Meyers FJ, Holcombe RF, Weiss GR, Mangalik A: Phase II study of fluorouracil and its modulation in advanced colorectal cancer: a Southwest Oncology Group Study. J Clin Oncol 1995, I3:|303-1311.

6. Creemers G], Lund B, Verweij J: Topoisomerase I inhibitors: topotecan and irinotecan. Cancer Treat Rev 1994, 20:73-96.

7. Conti JA, Kemeny NE, Saltz LB, Huang Y, Tong WP, Chou TC, Sun M, Pulliam S, Gonzalez C: Irinotecan is an active agent in untreated patients with metastatic colorectal cancer. J Clin Oncol 1996, | 4:709-7|5.

8. Pitot HC, Wender DB, O'Connell MJ, Schroeder G, Goldberg RM, Rubin J, Mailliard JA, Knost JA, Ghosh C, Kirschling RJ, Levitt R, Windschitl HE: Phase II trial of irinotecan in patients with metastatic colorectal carcinoma. J Clin Oncol 1997, 15:2910-2919.

9. Rougier $P$, Bugat R, Douillard JY, Culine S, Suc E, Brunet P, Becouarn Y, Ychou M, Marty M, Extra JM, Bonneterre J, Adenis A, Seitz JF, Ganem G, Namer M, Conroy T, Negrier S, Merrouche Y, Burki F, Mousseau M, Herait P, Mahjoubi M: Phase II study of irinotecan in the treatment of advanced colorectal cancer in chemotherapy-naive patients and pretreated patients with fluorouracil-based chemotherapy. J Clin Oncol 1997, I 5:25I-260.

10. Rothenberg ML, Eckardt JR, Kuhn JG, Burris HA, Nelson J, Hilsenbeck SG, Rodriguez GI, Thurman AM, Smith LS, Eckhardt SG, Weiss GR Elfring GL, Rinaldi DA, Schaaf LJ, Von Hoff DD: Phase II trial of irinotecan in patients with progressive or rapidly recurrent colorectal cancer. J Clin Oncol I996, I 4: I | 28- I I35.

II. Van Cutsem E, Cunningham D, Ten Bokkel Huinink WW, Punt CJ, Alexopoulos CG, Dirix L, Symann M, Blijham GH, Cholet P, Fillet G, Van Groeningen C, Vannetzel JM, Levi F, Panagos G, Unger C, Wils J, Cote $\mathrm{C}$, Blanc $\mathrm{C}$, Herait P, Bleiberg $\mathrm{H}$ : Clinical activity and benefit of irinotecan (CPT-II) in patients with colorectal cancer truly resistant to 5-fluorouracil (5-FU). Eur J Cancer 1999, 35:54-59.

12. Vanhoefer U, Harstrick A, Achterrath W, Cao S, Seeber S, Rustum YM: Irinotecan in the treatment of colorectal cancer: clinical overview. J Clin Oncol 200I, 19:150I-I5I8.

13. Cunningham D, Pyrhönen S, James RD, Punt CJ, Hickish TF, Heikkila R, Johannesen TB, Starkhammar H, Topham CA, Awad L, Jacques C, Herait $P$ : Randomised trial of irinotecan plus supportive care versus supportive care alone after fluorouracil failure for patients with metastatic colorectal cancer. Lancet 1998, 352:1413-1418

14. Rougier P, Van Cutsem E, Bajetta E, Niederle N, Possinger K, Labianca R, Navarro M, Morant R, Bleiberg H, Wils J, Awad L, Herait P, Jacques $C$ : Randomised trial of irinotecan versus fluorouracil by continuous infusion after failure in patients with metastatic colorectal cancer. Lancet I998, 352:1407-|4|2.

15. Saltz LB, Kanowitz J, Kemeny NE, Schaaf L, Spriggs D, Staton BA, Berkery R, Steger C, Eng M, Dietz A, Locker P, Kelsen DP: Phase I clinical and pharmacokinetic study of irinotecan, fluorouracil, and leucovorin in patients with advanced solid tumors. Clin Oncol 1996, 14:2959-2967.

16. Rothenberg ML, Pazdur R, Rowinsky EK, Cohn AL, Alberts DS, Petit RG, Miller LL, Elfring GL, Murphy TC, Mayer RJ: A phase II multicenter trial of alternating cycles of irinotecan and 5FU/LV in patients with previously untreated metastatic colorectal cancer [abstract]. Proc Am Soc Clin Oncol 1997, 16:266a.

17. Van Cutsem E, Pozzo C, Starkhammar H, Dirix L, Terzoli E, Cognetti F, Humblet Y, Garufi C, Filez L, Gruia G, Cote C, Barone C: A phase II study of irinotecan alternated with five days bolus of 5 fluorouracil and leucovorin in first line chemotherapy of metastatic colorectal cancer. Ann Oncol 1998, 9: | | 99- I 204.
18. Vanhoefer U, Harstrick A, Köhne CH, Achterrath W, Rustum YM, Seeber S, Wilke H: Phase I study of a weekly schedule of irinotecan, high dose leucovorin, and infusional fluorouracil as first-line chemotherapy in patients with advanced colorectal cancer. J Clin Oncol 1999, I7:907-913.

19. Ducreux M, Ychou M, Seitz JF, Bonnay M, Bexon A, Armand JP, Mahjoubi M, Mery-Mignard D, Rougier P: Irinotecan combined with bolus fluorouracil, continuous infusion fluorouracil, and highdose leucovorin every two weeks (LV5FU2 regimen): a dose finding and pharmacokinetic study in patients with pretreated metastatic colorectal cancer. J Clin Oncol 1999, I 7:290I-2908.

20. Saltz LB, Cox JV, Blanke C, Rosen LS, Fehrenbacher L, Moore MJ, Maroun JA, Ackland SP, Locker PK, Pirotta N, Elfring GL, Miller LL: Irinotecan plus fluorouracil and leucovorin for metastatic colorectal cancer. N Engl J Med 2000, 343:905-9/4.

21. Douillard JY, Cunningham D, Roth AD, Navarro M, James RD, Karasek P, Jandik P, Iveson T, Carmichael J, Alakl M, Gruia G, Awad L, Rougier P: Irinotecan combined with fluorouracil compared with fluorouracil alone as first-line treatment for metastatic colorectal cancer: a multicentre randomised trial. Lancet 2000, 355: 1041-1047.

22. Simon R: Optimal two-stage designs for phase II clinical trials. Controlled Clinical Trials 1998, 10: I-10.

23. Bouzid K, Hkalfallah S, Tujakowski J, Piko B, Purkalne G, Plate S, Padrik P, Serafy M, Pshevloutsky EM, Boussard B, Irinotecan Study Group: A randomized phase II trial of irinotecan in combination with infusional or two different bolus 5 -fluorouracil and folinic acid regimens as first-line therapy for advanced colorectal cancer. Ann Oncol 2003, I 4: I I 06- I I I4.

24. Glimelius B, Ristamaki R, Kjaer M, Pfeiffer P, Skovsgaard T, Tveit KM, Linne T, Frodin JE, Boussard B, Oulid-Aissa D, Pyrhonen S: Irinotecan combined with bolus 5 -fluorouracil and folinic acid Nordic schedule as first-line therapy in advanced colorectal cancer. Ann Oncol 2002, I3:1868-1873.

25. Rowinsky EK, Grochow LB, Ettinger DS, Sartorius SE, Lubejko BG, Chen TL, Rock MK, Donehower RC: Phase I and pharmacological study of the novel topoisomerase I inhibitor 7-ethyl-I0[4-(I-piperidino)-I piperidino] carbonyloxy camptothecin (CPT-II) administered as a ninety-minute infusion every 3 weeks. Cancer Res 1994, 54:427-436.

26. Abigerges D, Chabot GG, Armand JP, Hérait P, Gouyette A, Gandia $D$ : Phase I and pharmacologic studies of the camptothecin analog irinotecan administered every 3 weeks in cancer patients. I Clin Oncol 1995, I3:210-221.

27. Morton RF, Goldberg RM, Sargent DJ, Fuchs CS, O'Connell MJ: Oxaliplatin or CPT-II combined with 5-FU/Leucovorin in advanced colorectal cancer: an NCCTG/CALGB study [abstract]. Proc Am Soc Clin Oncol 200I, 20: I25a.

28. Rothenberg ML, Meropol NJ, Poplin EA, Van Cutsem E, Wadler S: Mortality associated with irinotecan plus bolus fluorouracil/ leucovorin: summary findings of an independent panel. J Clin Oncol 200I, 19:380I-3807.

29. Sargent DJ, Niedzwiecki D, O'Connell MJ, Schilsky RL: Recommendation for caution with irinotecan, fluorouracil, and leucovorin for colorectal cancer. N Engl J Med 200I, 345: | 44- I 45.

\section{Pre-publication history}

The pre-publication history for this paper can be accessed here:

http://www.biomedcentral.com/1471-2407/4/36/prepub 